\title{
FAKTOR-FAKTOR YANG MEMPENGARUHI NIAT MAHASISWA UNTUK BERWIRAUSAHA: APLIKASI THEORY OF PLANNED BEHAVIOR
}

\author{
Anik Sri Widawati \\ Alumni Program Magister Manajemen \\ Universitas Islam Indonesia \\ Budi Astuti \\ Pascasarjana Fakultas Ekonomi \\ Universitas Islam Indonesia \\ e-mail: twotiebudi@yahoo.com
}

\begin{abstract}
This study is a replication of research by Shook and Bratianu (2010). Variables that affect student intentions for entrepeneurship in this study are specific desirabilities, subjective norms, self-efficacy, perceived desirability and the perceived feasibility. Sampling was purposive sampling method. The number of samples of this study as much as 306 students. This study uses path analysis model with three channels equation. The result of path analysis in this study are as follows: 1) specifis desirabilities, subjective norms, and self-efficacy has positive and significant impact on entrepreneurial intentions, 2) perceived desirability of modifying the effect of specific desirabilities on intent entrepreneurship, 3) perceived feasibility to modify the effect of self-efficacy on entrepreneurship intentions. Desirabilities specific influence on entrepreneurial intentions became stronger after the mediation by the perceived desirability. Similarly, the influence of selfefficacy on entrepreneurial intentions became stronger after the mediation by the perceived feasibility. While the variables that have the most dominant influence in affecting entrepreneurial intentions are perceived desirability. The conclusion of this study is that the entrepreneurial intentions of students in assesment criteria very well. Therefore, entrepreneurship courses should be made as a compulsory subject for all courses.
\end{abstract}

Keywords: specific desirabilities, subjective norms, self-efficacy, perceived desirability and the perceived feasibility and entrepreneurship intentions.

\section{PENDAHULUAN}

Masalah pengangguran merupakan salah satu masalah penting yang terjadi di Indonesia. Jumlah lapangan pekerjaan yang terbatas telah meningkatkan jumlah pengangguran. Pengangguran di Indonesia, sebagian besar disumbangkan oleh lulusan dari perguruan tinggi yang jumlahnya sangat banyak. Hal ini bisa dilihat dari data Badan Statistik Nasional (BPS) tahun 2011 bahwa jumlah angkatan kerja yang menganggur hingga Februari 2011 mencapai 8,1 juta jiwa atau 6,80 persen dari total angkatan kerja. Dari jumlah tersebut
9,95 persen adalah sarjana dan 11,59 persen berpendidikan diploma.

Kondisi yang dihadapi akan semakin diperburuk dengan situasi persaingan global (misal pemberlakuan masyarakat ekonomi ASEAN/MEA) yang akan menghadapkan lulusan perguruan tinggi Indonesia bersaing secara bebas dengan lulusan dari perguruan tinggi asing (Suharti et al., 2011: 124). Lebih lanjut, bahwa para sarjana lulusan perguruan tinggi perlu diarahkan dan didukung untuk tidak hanya berorientasi sebagai pencari kerja (job seeker) namun dapat dan 
siap menjadi pencipta pekerjaan (job creator).

Solusi yang ditawarkan oleh pemerintah dalam rangka mengurangi angka pengangguran dengan cara menciptakan lapangan kerja bersifat padat karya. Namun demikian, kalangan terdidik cenderung untuk menghindari pilihan tersebut karena preferensi kerja mereka terhadap pekerjaan kantoran lebih tinggi. Preferensi yang lebih tinggi didasarkan pada perhitungan biaya yang telah dikeluarkan selama menempuh studi dan berharap tingkat pengembalian (rate of return) yang sebanding.

Masyarakat Indonesia cenderung memilih pekerjaan sebagai pegawai swasta ataupun negeri. Secara tidak langsung, pendidikan formal maupun non formal di Indonesia masih belum berorientasi pada kewirausahaan. Dalam keluarga, sebagian besar orang tua akan lebih bahagia dan merasa berhasil dalam mendidik anakanaknya, apabila anak dapat menjadi pegawai pemerintah maupun karyawan swasta yang jumlah penghasilannya jelas dan kontinyu setiap bulannya. Pendidikan di Indonesia juga membentuk peserta didik menjadi karyawan atau bekerja di perusahaan. Masyarakat cenderung lebih percaya diri bekerja pada orang lain daripada memulai usaha. Selain itu adanya kecenderungan menghindari risiko gagal dan pendapatan yang tidak tetap (Wijaya, 2008: 94).

Oleh karena itu, menumbuhkan jiwa kewirausahawan bagi mahasiswa perguruan tinggi dapat merupakan alternatif untuk mengurangi tingkat pengangguran. Menurut McClelland (1961, dalam Wijaya, 2008: 94) bahwa suatu negara akan maju jika terdapat entrepreneur minimal 2 persen dari jumlah penduduk. Sementara itu jumlah wirausaha Indonesia hanya sekitar 0,24 persen dari total penduduk Indonesia, tertinggal jauh dibandingkan negara-negara maju seperti Amerika yang mencapai 11,5 persen, Singapura memiliki 7,2 persen, dan Malaysia mencapai 5 persen (http://edukasi.kompas.com/read/2011/02 /27).

Salah satu faktor pendorong pertumbuhan kewirausahaan di suatu negara terletak pada peranan universitas melalui penyelenggaraan pendidikan kewirausahaan. Pihak universitas bertanggungjawab dalam mendidik dan memberikan kemampuan kewirausahaan kepada para lulusannya dan memberikan motivasi untuk berani memilih berwirausaha sebagai karir mereka (Zimmerer, 2002: 12). Sehingga pihak perguruan tinggi perlu menerapkan pola pembelajaran kewirausahaan yang konkrit berdasarkan masukan empiris untuk membekali mahasiswa dengan pengetahuan yang bermakna agar dapat mendorong semangat mahasiswa untuk berwirausaha (Yohnson, 2003: 110).

\section{KAJIAN PUSTAKA DAN HIPOTESIS Pengaruh Keinginan Spesifik (Specific Desirabilities) terhadap Niat Berwira- usaha}

Sikap terhadap perilaku mengacu pada sejauh mana seseorang memiliki evaluasi menguntungkan atau tidak menguntungkan atau penilaian terhadap perilaku tersebut (Ajzen, 1991 dalam Shook dan Bratianu, 2010: 234). Individu membentuk sikap terhadap suatu perilaku dengan mengkaitkannya pada kemungkinan hasil dari perilaku. Jika hasil terkait sebagian besar diinginkan, maka niat untuk melakukan perilakunya akan kuat. Namun jika terkait dengan sebagian besar yang tidak diinginkan, maka niat untuk melakukan perilakunya lebih lemah.

Dalam hal usaha, sikap penciptaan terhadap perilaku dapat dinilai cukup dengan mengevaluasi keinginan hasil terkait untuk menciptakan suatu perusahaan. Dalam konteks penciptaan usaha, persepsi individu tentang hasil positif biasanya terkait dengan memulai bisnis sendiri (misalnya kekayaan pribadi dan kebebasan) dan hasilnya negatif (misalnya stres) merupa- 
kan sikap terhadap perilaku (Shapero, 1982 dalam Shook dan Bratianu, 2010: 234).

Hasil penelitian empiris yang dilakukan oleh Krueger (1993, dalam Shook dan Bratianu, 2010: 235) menunjukkan bukti empiris bahwa jumlah keinginan tertentu (specific desirabilities) berpengaruh positif terhadap niat kewirausahaan. Oleh karena itu, hipotesis yang diajukan dalam penelitian ini adalah,

$\mathrm{H}_{1}$ : Keinginan Spesifik (Specific Desirabilities) berpengaruh positif terhadap niat berwirausaha.

\section{Pengaruh Norma Subyektif terhadap Niat berwirausaha}

Norma subyektif adalah keyakinan individu akan norma, orang sekitarnya dan motivasi individu untuk mengikuti norma tersebut (Fishbein et.al, 1975 dalam Wijaya 2008: 96). Lebih lanjut, bahwa di dalam norma subyektif terdapat dua aspek pokok yaitu keyakinan akan harapan dan harapan norma referensi, merupakan pandangan pihak lain yang dianggap penting oleh individu yang menyarankan individu untuk menampilkan atau tidak menampilkan perilaku tertentu serta motivasi kesediaan individu untuk melaksanakan pendapat atau pikiran pihak lain yang dianggap penting bahwa individu harus atau tidak harus berperilaku. Menurut theory of planned behavior, norma subyektif mempengaruhi niat seseorang untuk melakukan tindakan atau perilaku tertentu. Semakin kuat norma subyektif yang dihadapi konsumen, maka niatnya untuk melakukan perilaku tersebut semakin kuat. Hasil penelitian menunjukkan bukti empiris bahwa norma subyektif berpengaruh positif terhadap niat kewirausahaan pada siswa di Skandinavia (Autio et al., 2001 dalam Shook dan Bratianu, 2010: 236). Oleh karena itu, hipotesis yang diajukan dalam penelitian ini adalah:

$\mathrm{H}_{2}$ : Norma subyektif berpengaruh positif terhadap niat berwirausaha.

\section{Pengaruh Efikasi Diri (Self-Efficacy) terhadap Niat berwirausaha}

Efikasi diri akan karir seseorang adalah domain yang menggambarkan pendapat pribadi seseorang dalam hubungannya dengan proses pemilihan dan penyesuaian karir. Efikasi diri akan karir seseorang dapat menjadi faktor penting dalam penentuan apakah niat kewirausahaan seseorang sudah terbentuk pada tahapan awal seseorang memulai karirnya. Semakin tinggi tingkat efikasi diri seseorang pada kewirausahaan dalam berkarir, semakin kuat niat kewirausahaan yang dimilikinya (Hacket dan Betz, 1986 dalm Riyanti , 2008: 7).

Menurut theory of planned behavior, bahwa efikasi diri mempengaruhi niat seseorang untuk melakukan tindakan atau perilaku tertentu. Semakin kuat efikasi diri dari individu, maka niatnya untuk melakukan perilaku tersebut semakin kuat. Hasil penelitian empiris yang dilakukan oleh Shook dan Bratinau (2010: 236) menunjukkan bukti empiris bahwa efikasi diri berpengaruh positif dan signifikan pada niat untuk berperilaku. Oleh karena itu, hipotesis yang diajukan dalam penelitian ini adalah,

$\mathrm{H}_{3}$ : Efikasi diri berpengaruh positif terhadap niat berwirausaha.

Pengaruh Keinginan Yang Dirasakan (Perceived Desirability) dalam Memodifikasi Pengaruh Keinginan Spesifik (Specific Desirability) terhadap Niat Berwirausaha

Perceived desirability adalah daya tarik personal yang memandang penciptaan usaha baru sebagai sesuatu yang menarik dan diinginkan. Daya tarik ini tumbuh dari pandangan atas konsekuensi personal dalam pengalaman kewirausahaan (misalnya baik atau buruk), dan tingkat dukungan dari lingkungan (keluarga, teman, kerabat), sehingga merefleksikan afeksi individu terhadap kewirausahaan (Shapero dan Sokol, 1982 dalam Riyanti, 2008: 9). 
Setiap orang akan membandingkan keinginan (desirability) untuk bekerja secara mandiri atau bekerja sama pada orang lain (Segal et al., 2005 dalam Koesworo et al., 2006: 276). Sikap terhadap perilaku mengacu pada sejauh mana seseorang memiliki evaluasi menguntungkan atau tidak menguntungkan pada penilaian perilaku yang bersangkutan (Ajzen, 1991: 181). Jumlah dari keinginan tertentu akan berhubungan positif dengan niat kewirausahaan. Sejauh individu memiliki kesan holistik sangat menguntungkan untuk menciptakan usaha, maka akan cenderung memiliki niat untuk menciptakan usaha (Shook dan Bratianu, 2010: 237).

Hasil penelitian empiris yang dilakukan oleh Shook dan Bratianu (2010: 237) menunjukkan bukti empiris bahwa perceived desirability dapat memediasi hubungan antara specific desirabilities dengan niat untuk menjadi wirausaha. Oleh karena itu, hipotesis yang diajukan dalam penelitian ini adalah:

$\mathrm{H}_{4}$ : Keinginan yang dirasakan (Perceived Desirability) akan memodifikasi pengaruh Keinginan Spesifik (Specific Desirability) terhadap Niat berwirausaha.

\section{Pengaruh Kelayakan Yang Dirasakan (Perceived Feasibility) dalam Memodi- fikasi Pengaruh Efikasi Diri (Self- Efficacy) terhadap Niat Berwirausaha}

Perceived feasibility menunjukkan derajat kepercayaan dimana seseorang memandang dirinya mempunyai kemampuan untuk mengumpulkan sumberdaya (manusia, sosial dan finansial) untuk membangun usaha baru (Shapero dan Sokol, 1982 dalam Riyanti, 2008: 9). Variabel ini diukur dengan menggunakan satu indikator yang kemudian dirumuskan untuk mengevaluasi kepercayaan diri seseorang akan kemampuannya untuk menjalankan tugas dan aktivitas kewirausahaan (Segal et al., 2005: 50). Lebih lanjut, bahwa sejauh keyakinan individu dapat melakukan tugas-tugas yang terkait dengan pencip- taan usaha dari kelayakan, maka individu cenderung akan memiliki sebuah niat kewirausahaan.

Hasil penelitian empiris yang dilakukan oleh Shook dan Bratianu (2010: 237) menunjukkan bukti empiris bahwa perceived feasibility akan memediasi hubungan antara self-efficacy dengan niat untuk menjadi wirausaha. Oleh karena itu, hipotesis yang diajukan penelitian ini adalah:

$\mathrm{H}_{5}$ : Kelayakan yang dirasakan (Perceived Feasibility) akan memodifikasi pengaruh Efikasi Diri (Self-Efficacy) terhadap niat berwirausaha.

\section{Variabel Yang Paling Berpengaruh terhadap Niat untuk Berwirausaha}

Adanya berbagai kegiatan yang dilaksanakan di PT X, seperti career day, entrepreneur day, seminar kewirausahaan dan adanya pemilihan mahasiswa wirausaha diharapkan dapat menumbuhkan niat berwirausaha mahasiswa PT X. Sehingga penciptaan usaha baru diharapkan dapat menjadi sesuatu yang menarik dan diinginkan bagi mahasiswa PT X. Oleh karena itu hipotesis penelitian ini adalah:

$\mathrm{H}_{6}$ : Keinginan yang dirasakan (Perceived Desirability) merupakan variabel yang paling berpengaruh dalam mempengaruhi Niat berwirausaha.

\section{METODE}

Dalam penelitian ini, data primer diperoleh dengan menyebar kuesioner berskala likert dengan jumlah populasi dari mahasiswa yang sudah mengambil mata kuliah kewirausahaan sebesar 2.418 mahasiswa, sehingga jumlah sampel berdasar purposive sampling dalam penelitian ini adalah 306 mahasiswa.

Variabel penelitian terdiri dari, keinginan spesifik, norma subyektif, efikasi diri, keinginan yang dirasakan, kelayakan yang dirasakan dan niat berwirausaha dianalisis dengan analisis jalur (path analysis) model tiga jalur, sebagaimana tampak pada Gambar 1. 


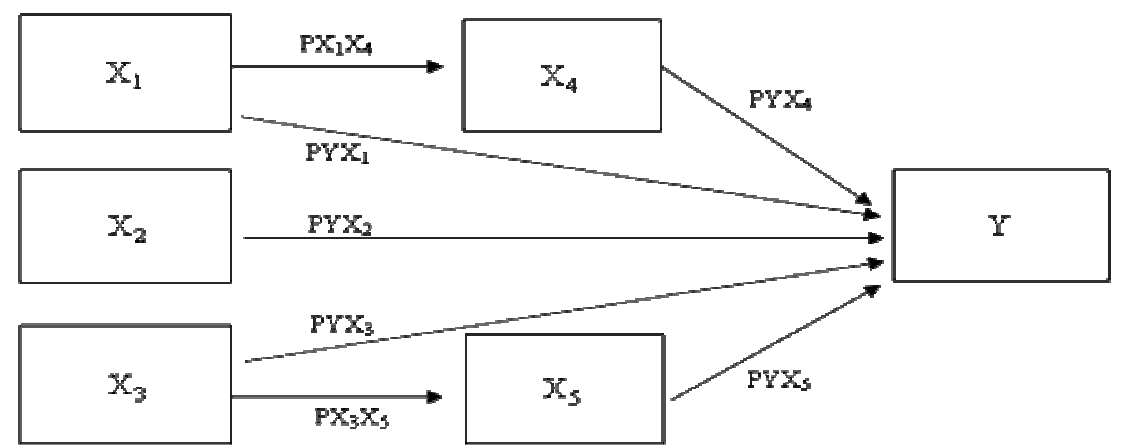

Gambar 1: Model Diagram Tiga Jalur

\section{HASIL DAN PEMBAHASAN}

Tabel 1: Hasil Analisis Jalur

\begin{tabular}{|c|c|c|c|c|}
\hline Model & Koefisien Jalur & Uji-t & Sig. & $\mathbf{R}^{2}$ \\
\hline \multicolumn{5}{|c|}{ Sub Struktural $1\left(X_{1} X_{2} X_{3}\right.$ ke $\left.Y\right)$} \\
\hline Konstanta & 3,245 & & & \multirow{4}{*}{0,280} \\
\hline$X_{1}\left(\mathrm{PYX} \mathrm{X}_{1}\right)$ & 0,164 & 3,117 & 0,002 & \\
\hline$X_{2}\left(\mathrm{P} Y X_{2}\right)$ & 0,262 & 4,938 & 0,000 & \\
\hline$X_{3}\left(P Y X_{3}\right)$ & 0,280 & 5,137 & 0,000 & \\
\hline \multicolumn{5}{|c|}{ Sub Struktural $2\left(X_{1}\right.$ ke $\left.X_{4}\right)$} \\
\hline Konstanta & 6,567 & & & \multirow[t]{2}{*}{0,264} \\
\hline$X_{1}\left(P X_{4} X_{1}\right)$ & 0,514 & 10,441 & 0,000 & \\
\hline \multicolumn{5}{|c|}{ Sub Struktural $3\left(X_{3}\right.$ ke $\left.X_{5}\right)$} \\
\hline Konstanta & 5,746 & & & \multirow[t]{2}{*}{0,244} \\
\hline $\mathrm{X}_{3}\left(\mathrm{P} \mathrm{X}_{5} \mathrm{X}_{3}\right)$ & 0,494 & 9,909 & 0,000 & \\
\hline \multicolumn{5}{|c|}{ Sub Struktural $4\left(X_{4} X_{5}\right.$ ke $\left.Y\right)$} \\
\hline Konstanta & 5,427 & & & \multirow{3}{*}{0,292} \\
\hline $\mathrm{X}_{4}\left(\mathrm{P} Y \mathrm{X}_{4}\right)$ & 0,372 & 7,127 & 0,000 & \\
\hline$X_{5}\left(P Y X_{5}\right)$ & 0,276 & 5,295 & 0,000 & \\
\hline
\end{tabular}

Sumber: Data Primer diolah

Hasil uji instrumen menunjukkan bahwa semua item pertanyaan dalam kuesioner dinyatakan valid dan reliabel, demikian pula dengan hasil uji asumsi klasik menghasilkan model yang yang layak untuk diteliti. Adapun hasil dari analisis jalur dengan model persamaan tiga jalur diuraikan sebagai tampak pada Tabel 1 di atas.

Persamaan regresi struktural pada analisis jalur penelitian ini sebagai berikut.

$Y=0,164 X_{1}+0,262 X_{2}+0,280 X_{3}+\epsilon_{1}$

$X_{4}=0,514 X_{1}+\epsilon_{2}$

$X_{5}=0,494 X_{3}+\epsilon_{3}$

$Y=0,372 X_{4}+0,276 X_{5}+\epsilon_{4}$

Dari hasil analisis sebagaimana terangkum dalam Tabel 1 maka dapat diketahui bahwa:

\section{Pengaruh Langsung (Direct Effect)}

- Pengaruh variabel specific desirabilities terhadap niat berwirausaha sebesar 0,164 .

- Pengaruh variabel norma subyektif terhadap niat berwirausaha sebesar 0,262

- Pengaruh variabel self-efficacy terhadap niat berwirausaha sebesar 0,280.

- Pengaruh variabel specific desirabilities terhadap perceived desirability sebesar 0,514 .

- Pengaruh variabel self-efficacy terhadap perceived feasibility sebesar 0,494.

- Pengaruh variabel perceived desirability terhadap niat berwirausaha sebesar 0,372 . 
- Pengaruh variabel perceived feasibility terhadap niat berwirausaha sebesar 0,276 .

- Variabel yang pengaruhnya paling besar terhadap niat berwirausaha adalah variabel perceived desirability yaitu sebesar 0,372.

Pengaruh Tidak Langsung (Indirect Effect)

- Pengaruh variabel specific desirabilities terhadap niat berwirausaha melalui perceived desirability sebesar 0,191.

$\mathrm{X}_{1} \quad \mathrm{X}_{4} \quad \mathrm{Y}=0,514 * 0,372=0,191$

- Pengaruh variabel self-efficacfy terhadap niat berwirausaha melalui perceived feasibility sebesar 0,136.

$X_{3} \quad X_{5} \quad Y=0,494 * 0,276=0,136$

\section{Pengaruh Total}

- Pengaruh variabel specific desirabilities terhadap niat berwirausaha melalui perceived desirability sebesar 0,886 .

$\mathrm{DE} \mathrm{X}_{1} \quad \mathrm{X}_{4}+\mathrm{X}_{4} \quad \mathrm{Y}=0,514+0,372=$ 0,886

- Pengaruh variabel self-efficacy terhadap niat berwirausaha melalui perceived feasibility sebesar 0,770 .

$\mathrm{DE} \mathrm{X}_{3} \quad \mathrm{X}_{5}+\mathrm{X}_{5} \quad \mathrm{Y}=0,494+0,276=$ 0,770

Uji Hipotesis secara parsial (Uji t)

Pengaruh Keinginan Specifik (Specific Desirabilities) terhadap Niat Berwirausaha

Berdasarkan hasil analisis regresi yang disajikan dalam Tabel 1 bahwa variabel specific desirabilities memiliki koefisien positif sebesar 0,164 artinya jika specific desirabilities meningkat sebesar satu satuan maka niat berwirausaha naik sebesar 0,164 dengan anggapan variabel lainnya tetap. Pada tingkat signifikansi $5 \%$, maka nilai sig. penelitian $(0,002)<0,05$ sehingga hipotesis penelitian ini diterima kebenarannya.

Kesimpulan dari hasil pengujian hipotesis ini adalah bahwa keinginan spesifik (specific desirabilities) berpengaruh positif dan signifikan terhadap niat berwirausaha. Artinya semakin baik specific desirabilities maka semakin baik niatnya untuk berwirausaha.
Pengaruh Norma Subyektif terhadap Niat Berwirausaha

Berdasarkan hasil analisis regresi yang disajikan dalam Tabel 1, variabel norma subyektif memiliki koefisien positif sebesar 0,262 artinya jika norma subyektif meningkat sebesar satu satuan maka niat berwirausaha naik sebesar 0,262 dengan anggapan variabel lainnya tetap. Pada tingkat signifikansi 5\%, maka nilai signifikansi penelitian $(0,000)<0,05$ sehingga hipotesis penelitian ini diterima kebenarannya.

Kesimpulan dari hasil pengujian hipotesis ini adalah bahwa norma subyektif berpengaruh positif dan signifikan terhadap niat berwirausaha. Artinya semakin baik norma subyektif, maka semakin baik niatnya untuk berwirausaha.

\section{Pengaruh Efikasi Diri (Self-Efficacy) terhadap Niat Berwirausaha}

Berdasarkan hasil analisis regresi yang disajikan dalam Tabel 1 variabel self-efficacy memiliki koefisien positif sebesar 0,280 artinya jika self-efficacy meningkat sebesar satu satuan maka niat berwirausaha naik sebesar 0,280 dengan anggapan variabel lainnya tetap. Pada tingkat signifikansi 5\%, maka nilai signifkansi penelitian $(0,000)<$ 0,05 sehingga hipotesis penelitian ini diterima kebenarannya.

Kesimpulan dari hasil pengujian hipotesis ini adalah bahwa efikasi diri (selfefficacy) berpengaruh positif dan signifikan terhadap niat berwirausaha. Artinya semakin baik self-efficacy, maka semakin baik niatnya untuk berwirausaha.

Pengaruh Keinginan yang Dirasakan (Perceived Desirability) dalam Memodifikasi Pengaruh Keinginan Spesifik (Specific Desirabilities) terhadap Niat Berwirausaha

Berdasarkan hasil analisis jalur pada pengaruh total bahwa variabel perceived desirability memiliki koefisien positif sebesar 0,886 artinya jika perceived desirability meningkat sebesar satu satuan maka akan memodifikasi pengaruh specific desirabilities 
terhadap niat berwirausaha naik sebesar 0,886 dengan anggapan variabel lainnya tetap. Pada tingkat signifikansi 5\%, maka nilai signifikansi penelitian $(0,000)<0,05$ sehingga hipotesis penelitian ini diterima kebenarannya.

Kesimpulan dari hasil pengujian hipotesis ini adalah bahwa keinginan yang dirasakan (perceived desirability) akan memodifikasi pengaruh keinginan spesifik (specific desirabilities) terhadap niat berwirausaha. Artinya semakin baik perceived desirability, maka semakin baik dalam memodifikasi pengaruh specific desirabilities terhadap niat untuk berwirausaha.

Pengaruh Kelayakan yang Dirasakan (Perceived Feasibility) dalam Memodifikasi Pengaruh Efikasi Diri (Self-Efficacy) terhadap Niat Berwirausaha

Berdasarkan hasil analisis jalur bahwa variabel perceived feasibility memiliki koefisien positif sebesar 0,770 artinya jika perceived feasibility meningkat sebesar satu satuan maka akan memodifikasi pengaruh self-efficacy terhadap niat berwirausaha naik sebesar 0,770 dengan anggapan variabel lainnya tetap. Pada tingkat signifikansi 5\%, maka nilai signifikansi penelitian $(0,000)<0,05$ sehingga hipotesis penelitian ini diterima kebenarannya.

Kesimpulan dari hasil pengujian hipotesis ini adalah bahwa kelayakan yang dirasakan akan memodifikasi pengaruh efikasi diri (self-efficacy) terhadap niat berwirausaha. Artinya semakin baik perceived feasibility, maka semakin baik dalam memodifikasi pengaruh self-efficacy terhadap niat untuk berwirausaha.
Keinginan yang dirasakan (Perceived Desirability) Merupakan Variabel yang Paling Dominan dalam Mempengaruhi Niat Berwirausaha

Berdasarkan hasil analisis regresi yang disajikan dalam Tabel 1 variabel perceived desirability memiliki koefisien positif sebesar 0,372 yang merupakan nilai yang paling besar dalam mempengaruhi niat untuk berwirausaha. Pada tingkat signifikansi $5 \%$, maka nilai sig. penelitian $(0,000)<0,05$ sehingga hipotesis penelitian ini diterima kebenarannya. Kesimpulan dari hasil pengujian hipotesis ini adalah bahwa perceived desirability merupakan variabel yang paling dominan dalam mempengaruhi niat untuk berwirausaha mahasiswa.

\section{Uji Koefisien Determinasi Berganda $\left(\mathbf{R}^{2}\right)$}

Hasil uji koefisien determinasi berganda tampak pada Tabel 2. Oleh karena penelitian ini menggunakan analisis jalur, maka nilai koefisien determinasi total menggunakan rumus sebagai berikut.

$\mathrm{R}_{\mathrm{T}}{ }^{2}=1-\left[\left(1-\mathrm{R}_{1}{ }^{2}\right)\left(1-\mathrm{R}_{2}{ }^{2}\right)\left(1-\mathrm{R}_{3}{ }^{2}\right)\left(1-\mathrm{R}_{4}{ }^{2}\right)\right]$

Artinya, jika misalnya $X_{1} \quad X_{4} \quad Y$ $<$ dari $X_{1} Y$, maka dikatakan $X_{4}$ tidak signifikan atau tidak punya pengaruh apaapa terhadap $Y$, sedangkan jika $X_{1} \quad X_{4}$ $\mathrm{Y}>$ dari $\mathrm{X}_{1} \quad \mathrm{Y}$ maka dikatakan $\mathrm{X}_{4}$ signifikan sehingga untuk mencapai $Y$ harus melalui $X_{4}$. Koefisien determinasi total dalam penelitian ini adalah sebesar 0,716 atau $71,6 \%$ sehingga model dalam penelitian ini sudah baik, sebab variabel-variabel yang digunakan memiliki pengaruh $71,6 \%$ dan sisanya $28,4 \%$ dipengaruhi oleh variabel lain diluar penelitian ini.

Tabel 2: Hasil Uji Koefisien Determinasi

\begin{tabular}{ccccc}
\hline Model & R & R Square & Adjusted R Square & Std Error of the Estimate \\
\hline 1 & 0,529 & 0,280 & 0,272 & 1,61921 \\
2 & 0,514 & 0,264 & 0,262 & 1,66971 \\
3 & 0,494 & 0,244 & 0,242 & 2,29002 \\
4 & 0,540 & 0,292 & 0,287 & 1,60265 \\
\hline
\end{tabular}

Hasil $\mathrm{R}_{\mathrm{T}}^{2}=0,716$

Sumber: Data Primer diolah 


\section{PENUTUP}

\section{Simpulan}

Berdasarkan analisis dan pembahasan yang telah dilakukan, maka dapat ditarik kesimpulan sebagai berikut. 1) Keinginan spesifik (specific desirabilities) berpengaruh positif terhadap niat berwirausaha. Artinya semakin baik keinginan spesifik (specific desirabilities) maka semakin baik niat berwirausaha mahasiswa. 2) Norma subyektif berpengaruh positif terhadap niat berwirausaha. Artinya semakin baik norma subyektif maka semakin baik niat berwirausaha mahasiswa. 3) Efikasi diri (self-efficacy) berpengaruh positif terhadap niat berwirausaha. Artinya semakin baik efikasi diri (self- efficacy) maka semakin baik niat berwirausaha mahasiswa. 4) Keinginan yang dirasakan (perceived desirability memodifikasi pengaruh keinginan spesifik (specific desirabilities) terhadap niat berwirausaha. Artinya semakin baik perceived desirability, maka semakin baik dalam memodifikasi pengaruh specific desirabilities terhadap niat untuk berwirausaha mahasiswa. 5) Kelayakan yang dirasakan (perceived feasibility) memodifikasi pengaruh efikasi diri (self-efficacy) terhadap niat berwirausaha. Artinya semakin baik perceived feasibility, maka semakin baik dalam memodifikasi pengaruh self-efficacy terhadap niat untuk berwirausaha mahasiswa. 6) Variabel Perceived Desirability mempunyai pengaruh yang paling dominan dalam mempengaruhi niat berwira- usaha mahasiswa. Hal ini dikarenakan bahwa mahasiswa memandang bahwa penciptaan usaha baru sebagai sesuatu yang menarik dan diinginkan. Daya tarik ini tumbuh karena didukung adanya berbagai kegiatan yang dilaksanakan di PT X, seperti career day, entrepreneur day, seminar kewirausahaan dan adanya pemilihan mahasiswa wirausaha.

\section{Implikasi Penelitian dan Saran Untuk Penelitian Berikutnya}

Berdasarkan hasil penelitian dan analisis yang telah dilakukan maka dapat disampaikan saran sebagai berikut. 1) Mata kuliah kewirausahaan sebaiknya sebagai mata kuliah wajib bagi mahasiswa dan diberlakukan untuk semua program studi. 2)Niat berwirausaha mahasiswa sangat tinggi, sehingga perlu adanya pola pembelajaran kewirausahaan yang lebih konkrit. Kurikulum yang ada di desain sedemikian rupa sehingga tidak hanya teori, tetapi juga praktik pembuatan usaha baru. 3) Kegiatan entrepreneur campus, seharusnya lebih dimaksimalkan dalam mengadakan kegiatan pelatihan kepada mahasiswa. 4) Untuk penelitian selanjutnya diharapkan adanya penambahan variabel lain seperti faktor demografi (gender, pengalaman bisnis keluarga). Sehingga mampu mengungkapkan lebih banyak faktor yang mempengaruhi niat berwirausaha pada mahasiswa.

\section{DAFTAR PUSTAKA}

Ajzen, Icek., (1991), “The Theory of Planned Behavior”, Organizational Behavior and Human Decision Process, 50, pp. 179-211.

Autio, E., Keeley, R.H., Klofsten, M., Parker, G.G.C., \& Hay, M., (2001), “Entrepreneurial Intent Among Student in Scandinavia and in the USA", Enterprise and Innovation Management Studies, 2, pp. 145-160

Fishbein, M., et al., \& Ajzen, Icek., (1975), Belief, Attitude, Intention and Behavior: An Introduction to Theory and Research. Addison-Wesley Publishing Company Inc, Menlo Park, California.

Hacket, G., \& N. E. Betz, (1986), “Application of Self Efficacy Theory to Understanding Career Choice Behaviour", Journal of Social Clinical and Psychology, 4, pp. 279-289. 
Koesworo, Y., Sina, S., \& Nugeraheni, D., (2006), "Motivasi Berwirausaha di Kalangan Mahasiswa: Aplikasi Theory of Planned Behavior". Jurnal Ekuitas, 11, pp.269-291

Krueger, N., (1993), “The Impact of Prior Entreprenuerial Exposure on Perceptions of New Venture Feasibility and Deserability", Entrepreneurship: Theory and Practice, 18 (1), pp. 5-21.

Mc.Clelland, D.C., (1961). The Achieving Society. Van Nostrand, Priceton, NJ.

Riyanti, B.P.D., (2008), Metode Experiental Learning Berbasis Pada Peningkatan Rasa Diri Mampu, Kreatif dan Berani Berisiko dalam Mata Pelajaran Kewirausahaan untuk SMK, Jakarta, Unika Atmajaya

Shapero, A., (1982), Social Dimension of Entrepreneurship, Prentice-Hall Englewood Cliffs, N.J.

Sewell, A. \& George, A., (2000), "Developing Efficacy Beliefs in the Classroom", The Journal of Educatioal Enquiry, 1, (2)

Segal, G., \& Borgia, D., Schoenfeld, J., (2005), “The Motivation to Become an Entrepreneur", International Journal of Entrepreneurial Behavior \& Research, 11, pp. 42-57.

Shapero, Albert and Sokol, Lisa, (1982), "The Social Dimensions of Entrepreneurship". Encyclopedia of Entrepreneurship, pp. 72-90.

Shook, C.R. \& Bratianu, C., (2010), "Entrepreneurial Intent in a Transitional Economy: an Application of the Theory of Planned Behavior to Romanian Students", International Entrepreneurship Management Journal.

Suharti, L., \& Sirine, H., (2011), "Faktor-faktor yang Berpengaruh Terhadap Niat Kewirausahaan (Entrepreneurial Intention) (Studi Terhadap Mahasiswa Universitas Kristen Satya Wacana, Salatiga)" Jurnal Manajemen dan Kewirausahaan, 13, pp. 124134.

Sugiyono, (2011), Metode Penelitian Kuantitatif Kualitatif dan $R \mathcal{E}$ D. Penerbit Alfabeta, Bandung.

Wijaya, Tony, (2008), Kajian Model Empiris Perilaku Berwirausaha UKM DIY dan Jawa Tengah. Jurnal Manajemen dan Kewirausahaan, 2, pp. 93-104.

Yohnson, (2003), Peranan Universitas dalam Memotivasi Sarjana Menjadi Young Entrepreneurs. Jurnal Manajemen dan Kewirausahaan, 5, pp. 97-111.

Zimmerer, W.T., (2002), Essentials of Entrepreneurship and Small Business Management. Third Edition. New York: Prentice-Hall. 